
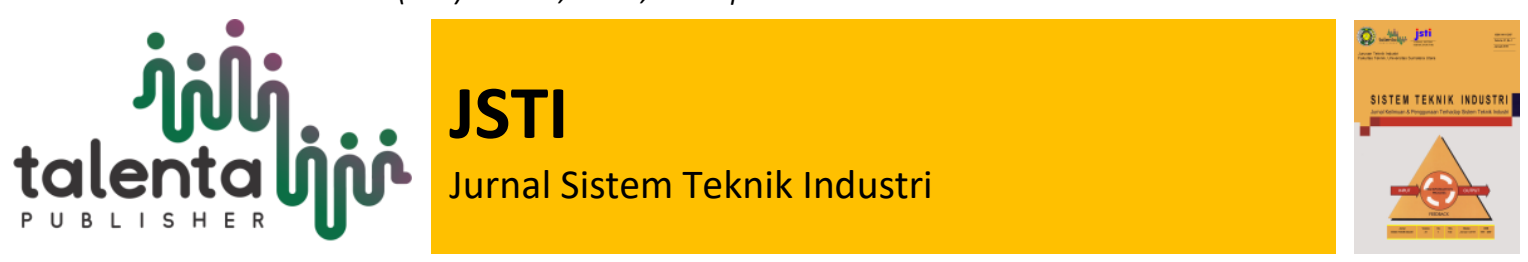

\title{
Desain Meja dan Kursi Tutorial Laboratorium Desain Produk dan Inovasi Menggunakan Metode 12 Prinsip Ergonomi dan Pendekatan Antropometri
}

\author{
Helena Hotmauli Sinaga ${ }^{1}$, Benedikta Anna Haulian Siboro ${ }^{2}$, Chrisdio \\ Marbun $^{3}$ \\ 1,2,3 Program Studi Manajemen Rekayasa, Fakultas Teknologi Industri, Institut Teknologi Del, Sitoluama, \\ Sumatera Utara
}

\begin{abstract}
The laboratory has an important thing to in producing graduates who are ready to work. In the laboratory itself, of course, it requires supporting facilities so that the participants can carry out learning activities properly. This is the same as the activity of developing a Product Design and Innovation laboratory at the Institut Teknologi Del which requires supporting facilities for its users. The purpose of this research is to design ergonomic desk and chair tutorial facilities that meets to users requirement. The method this research uses 12 ergonomic principles to identify user needs and translate them into Ergonomic Function Deployment (EFD) to develop House of Quality(HOQ) and designed by an anthropometric approach. The results of this study are the design of the tutorial desk and chair facilities with the 5-95th percentile of student body to meet their design use.
\end{abstract}

Keyword: Tutorial Desk, Tutorial Chair, 12 Ergnomic Principles, Ergonomic Function Deployment, Anthropometry, Percentile

\begin{abstract}
Abstrak. Laboratorium memiliki peranan penting dalam menghasilkan lulusan yang siap kerja. Dalam laboratorium sendiri tentunya membutuhkan fasilitas pendukung agar pesertanya dapat melakukan kegiatan pembelajaran dengan baik. Hal ini sama dengan kegiatan pembangungan Laboratorium Desain Produk dan Inovasi di Institut Teknologi Del yang membutuhkan fasilitas pendukung untuk para penggunanya. Penelitian ini bertujuan untuk mendesain fasilitas meja dan kursi tutorial yang ergonomis yang sesuai dengan kebutuhan calon penggunanya. Metode yang digunakan dalam perancangan ini menggunakan 12 prinsip ergonomi untuk mengidentifikasi kebutuhan pengguna dan menuangkannya ke dalam Ergonomic Function Deployment (EFD) untuk membangun House of Quality $(H O Q)$ serta dirancang pendekatan antropometri. Hasil dari penelitian ini desain fasilitas meja tutorial dan kursi dengan persentil 5-95 dari dimensi tubuh mahasiswa yang sesuai kegunaanya dalam desain.
\end{abstract}

Kata Kunci: Meja tutorial, Kursi Tutorial, 12 prinsip Ergonomi, Ergonomic Function Deployment, Antropometri, Persentil

Received 12 November 2020 | Revised 21 December 2020 | Accepted 21 January 2021

*Corresponding author at: Institut Teknologi Del, Toba, Indonesia 


\section{Pendahuluan}

Dalam mempersiapkan lulusan yang siap kerja dan mudah diserap sesuai dengan kebutuhan dunia kerja, maka penting adanya sistem link and match antara perguruan tinggi dan sektor industri [1]. Untuk mewujudkan berjalannya sistem tersebut maka sebuah pendidikan tinggi diharapkan mampu mempersiapkan mahasiswa agar mempunyaikualitas terhadap pengalaman dan kemampuan yang diperlukan industri. Salah satu variabel yang berpengaruh pada kualitas kelulusan pendidikan tinggi adalah sarana dan prasarana yang mencakup kondisi gedung, keberadaan laboratorium, perlengkapan penunjang pembelajaran [2]. Laboratorium sendiri dapat diartikan sebagai ruangan yang digunakan untuk melakukan percobaan dan penelitian. Selain itu laboratorium merupakan salah satu prasarana pembelajaran yang digunakan sebagai tempat bagi mahasiswa untuk melatih dalam memahami konsep-konsep yang sudah didapatnya sehingga meningkatkan keterampilan dalam melakukan percobaan ilmiah [3].

Proses pencapaian tujuan peningkatan kualitas lulusan pada Institut Teknologi Del dituangkan dalam salah satu program kerja yang ada dalam Rencana Strategis Fakultas Teknologi Industri IT Del pada tahun 2019 yaitu Pembangunan Laboratorium Desain Produk dan Inovasi (Desprin). Kedudukan Laboratorium Desprin ini dalam peta kompetensi kurikulum Program Studi Manajemen Rekayasa mengacu pada literatur-literatur ilmiah mengenai tubuh pengetahuan (body of knowledge) Manajemen Rekayasa yang dirumuskan dalam delapan kelompok bahan kajian yang terintegrasi dan tertuang dalam mata kuliah yang sesuai dengan disain produk seperti Visualisasi dan Gambar Teknik, Desain Proyek Rekayasa, Perancangan dan Pengembangan Produk, Perancangan Produk Inovatif dan Tugas Akhir.

Dalam mewujudkan Laboratorium Desprin sebagai pusat aktivitas berlatih dan mempraktekkan hasil teori yang didapat oleh mahasiswa, maka diperlukan disediakan fasilitas yang mumpuni dan berisi modul pelatihannya yang disesuaikan dengan perkembangan dunia industri dan jasa [4]. Dalam penelitian ini fasilitas yang akan didesain adalah meja dan kursi tutorial. Dimensi meja dan kursi tutorial didesain sesuai dengan antropometri dari mahasiswa yang mempertimbangkan aspek fungsionalitas dan ergonomis sehingga dapat mempertahankan postur tulang punggung yang fisiologis, yang pada akhirnya diharapkan kerja otot tidak berkontraksi secara berlebihan [5]. Desain kusi akan mempertimbangkan berat badan yang disangga oleh tulang duduk sehingga pengguna mampu bertahan pada posisi duduk dengan nyaman [6]. Meja belajar merupakan alas yang digunakan saat melakukan aktivitas belajar sehingga diperlukan desain dengan dimensi yang sesuai dengan postur tubuh sehingga dapat mengurangi sakit pinggang atau punggung, otototot leher dan bahu [7].

Dalam pemenuhan dan perancangan permintaan akan fasilitas meja dan kursi tutorial pada laboratorium ini diperlukan desain yang nyaman dan sesuai dengan permintaan calon pengguna. Sehingga untuk menfasilitasi permintaan pengguna, maka diperlukan penyebaran kuesioner yang 
nantinya akan dapat disimpulkan dan diterjemahkan dengan menggunakan ergonomic function deployment yang berdasarkan pada 12 prinsip ergonomi sehingga factor ENASE (Efektif, Nyaman, Aman, Sehat, Efisien) pada meja dan kursi tutorial yang ergonomis dapat terwujud [8][9]

\section{Metode Penelitian}

Penelitian ini dilakukan di Institut Teknologi Del dengan objek penelitian mahasiswa Manajemen Rekayasa dan jumlah dari sampel yang akan dipergunakan sebanyak 112 sampel yang dihitung dengan menggunakan rumus slovin [10]. Adapun data yang diperlukan pada penelitian ini adalah

1. Data antropometri mahasiswa

2. Data kuisioner yang bertujuan untuk mengidentifikasi voice of customer yang berisi komponen-komponen 12 prinsip ergonomi. Data ini selanjutnya akan diolah untuk membangun House of Ergonomic (HOE) yang pada akhirnya akan menghasilkan spesifikasi yang dibutuhkan oleh pengguna dari kursi dan meja tutorial tersebut.

Penelitian ini menggunakan perangkat lunak CAD (Computer Aided Design) dalam mendesainkursi dan meja tutorial.

\subsection{Ergonomic Function Deployment (EFD)}

EFD adalah pengembangan dari Quality Function Deployment [11] yang berfokus padahubungan antara keinginan dari pelanggan dan aspek ergonomis produk. Hubungan ini kemudian dibentuk dalam matriks House of Quality pada Ergonomic Function Deployment seperti pada Gambar 1 [12].

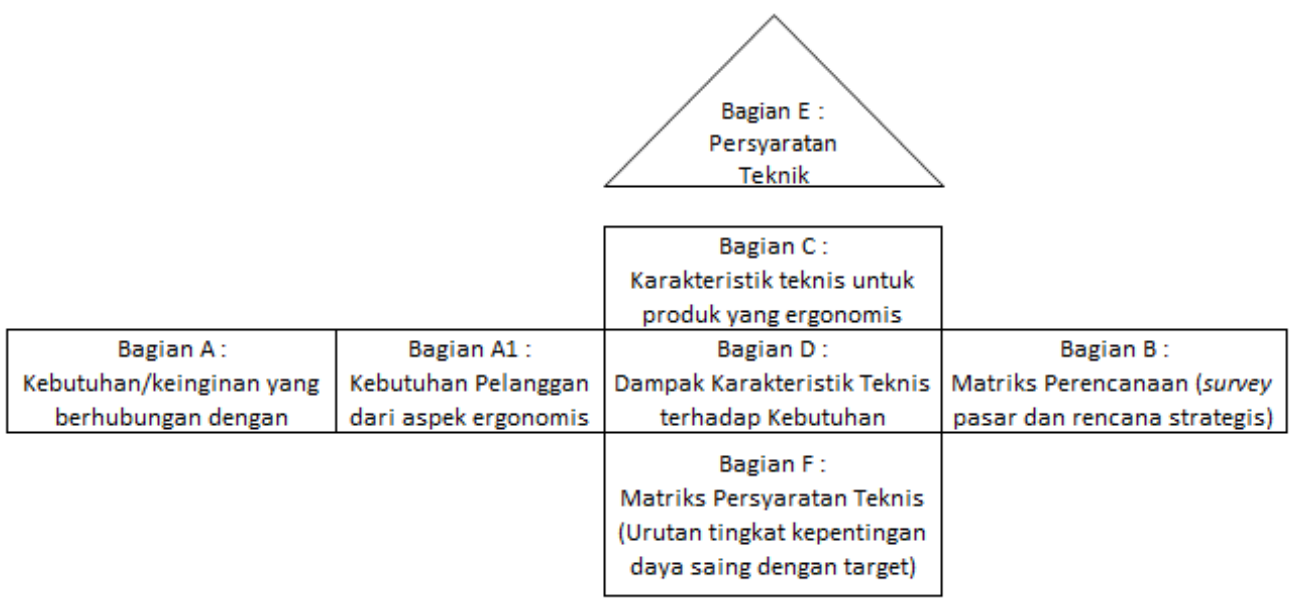

Gambar 1 House of Quality Ergonomic Function Deployment 
1. A: Pada bagian ini menjelaskan tentang sejumlah kebutuhan dan keinginan pelanggan yang ditentukan berdasarkan penelitian pasar kualitatif.

2. A1: Bagian ini menterjemahkan kebutuhan konsumen yang ditinjau dari aspek ergonomi.

3. B: Bagian ini berisi (1) Derajat kepentingan, kebutuhan dan keinginan konsumen. (2) Tingkat kepuasan konsumen terhadap produk competitor (3) Tujuan strategis untuk mengembangkan produk atau jasa baru. Adapun tingkat kepentingan yang dipaparkan merupakan hasil perhitungan dengan menggunakan rumus (1) dengan rentang kepentingan 1 hingga 5 (semakin tinggi semakin penting) [13]. Pada HOQ terdapat Technical requirement yang merupakan bentuk teknis pembuatan produk yang akan dibuat. Hubungan voice of customer dan Technical Requirement akan dipaparkan dalam HOQ baik itu hubungan kuat (•), sedang (०), maupun lemah $(\nabla)$.

4. $C$ : Bagian ini menjelaskan karakteristik teknis untuk produk yang dirancang dan merupakan translasi dari apa yang menjadi keperluankonsumen.

5. D: Bagian ini terdiri dari pemberian nilai manajemen mengenai kekuatan relasi antara elemenelemen pada persyaratan teknis (matriks $\mathrm{C}$ ) terhadap keperluanpelanggan (matriks $\mathrm{A}$ ) yang

6. E: Bagian ini merupakan matriks korelasi teknisyang berbentukseperti atap (roof) yang dipergunakan untuk mengidentifikasikan pertukaran atribut dan menunjukkan relasi antara atribut yang satu dengan yang lain.

7. F: Technical response priorities, competitive technical benchmarking, target technical.

Dalam mengumpulkan data EFD, maka pada idea screening menggunakan 12 prinsip ergonomi [14]. Adapun 12 prinsip tersebut terdiri dari[15][16]:

1. Bekerja pada postur tubuh yang normal

2. Meminimalisai beban atau beban berlebih

3. Menempatkan peralatan yang mudah dijangkau

4. Bekerja pada ketinggian yang sesuai dengan dimensi tubuh

5. Mengurangi gerakan berlebihan atau berulang

6. Meminimalisai adanya beban atau gerakan statis

7. Minimalisasi adanya resiko titik beban

8. Lebih leluasa bergerak pada ruang atau area kerja

9. Melakukan gerakan dan peregangan

10. Menjaga Kenyamanan lingkungan

11. Membuat display dan kontrol

12. Meningkatkan organisasi kerja

\subsection{Antropometri}

Antropometri secara luas diaplikasikan dalam proses perancangan produk dengan mempertimbangkan aspek ergonomis. Data antropometri pada dasarnya akan berbeda berdasarkan beberapa kelompok data berdasarkan usia, jenis kelamin,etnis, pekerjaan. dan posisi tubuh[17][18]. Sehingga berdasarkan antropometri berperan dalam perancangan produk yang bisa 
disesuaikan dengan dimensi tubuh orang yang akan mengoperasikannya [19]. Bagian dimensi dimensi antropometri yang dibutuhkan dalam perancangan meja dan kursi belajar adalah [20]:

1. Tinggi Bahu pada posisi Duduk (TBD)

2. Tinggi Siku pada posisi Duduk (TSD)

3. Tebal Paha (TP)

4. Tinggi Popliteal (TPO)

5. Panjang Popliteal (PP)

6. Lebar Pinggul (LP)

7. Lebar Bahu (LB)

8. Rentangan Tangan (RT)

Dalam mengolah data antropometri dari masing-masing dimensi data maka diperlukan pengujian data untuk memastikan data yang digunakan tidak memiliki perbedaan yang signifikan antar data yang digunakan. Beberapa pengujian pada peneltian ini yaitu:

1. Uji Normalitas, digunakan untuk mengetahui sebaran data pada populasi normal terdistribusi normal atau tidak[21]. Uji Normalitas dilakukan dengan menggunakan Uji Kolmogorov-Smirnov [22]dengan SPSS dengan hipotesis sebagai berikut:

Ho: Nilai signifikansi > 0,05, data berdistribusi normal Hi: Nilai signifikansi $<0,05$, data tidak berdistribusi normal

2. Uji kecukupan data merupakan proses pengujian untuk memastikan pemenuhan jumlah sampel secara obyektif [23]. Rumus yang digunakan pada pengujian ini yaitu:

$$
N^{\prime}=\left[\frac{\mathrm{k} / \mathrm{s} \sqrt{\mathrm{N} \sum \mathrm{X}^{2}-\left(\sum \mathrm{X}\right)^{2}}}{\sum \mathrm{X}}\right]^{2}
$$

Keterangan:

$\mathrm{N}^{\prime}=$ Jumlah data yang seharusnya

$\mathrm{N}=$ Jumlah pengamatan

$\mathrm{Xi}=$ Data pengukuran

$\mathrm{s}=$ Derajat ketelitian yang digunakan

$\mathrm{k}$ = tingkat keyakinan

3. Uji keseragaman data, bertujuan agar data yang diukur telah seragam dan berada dalam batas kendali atas (BKA) dan batas kendali bawah (BKB) [24]. Pada bagian ini rumus yang digunakan adalah: 


$$
\begin{aligned}
& \mathrm{BKA}=\overline{\overline{\mathrm{X}}}+3 \sigma \\
& \mathrm{BKA}=\overline{\overline{\mathrm{X}}}-3 \sigma
\end{aligned}
$$

Keterangan:

$\mathrm{BKA}=$ Batas Kendali Atas

$\mathrm{BKB}=$ Batas Kendali Bawah

$\overline{\bar{X}}=$ Nilai rata-rata sampel

$\sigma=$ Standar deviasi

\section{Hasil dan Pembahasan}

Pembangunan Laboratorium Desprin direncanakan akan berada di Lantai 1, Gedung 9 Fakultas Teknologi Industri, Institut Teknologi Del. Ruangan yang akan menjadi laboratorium ini berukuran $18 \mathrm{~m} \times 15 \mathrm{~m}$ dengan kapasitas maksimum 60 orang. Prasarana dan sarana guna meningkatkan kualitas pendidikan dilakukan dengan beberapa tahapan dan salah satunya adalah desain fasilitas belajar mengajar berupa meja dan kursi tutorial.

\subsection{Identifikasi Voice of Customer (VoC) dan Technical Requirement (TR)}

Identifikasi data kebutuhan konsumen diperoleh melalui kuisioner yang mengaplikasi konsep 12 prinsip ergonomi ke dalam bentuk pertanyaan. Sebagai contoh prinsip yang pertama yaitu bekerja pada posisi netral yang menghasilkan VoC kursi memenuhi posisi duduk normal dan ketinggiannya dapat diukur. Sedangkan untuk hasil TR pada prinsip yang pertama adalah kursi harus sesuai dengan bentuk punggung dan kursi dapat dinaikturunkan (Tabel 1).Hal ini juga dilakukan pada desain meja dengan membangun VoC berdasarkan 12 prinsip ergonomi (Tabel 2).

Tabel 1 VoC, Tingkat Kepentingandan Technical Requirement Kursi Tutorial

\begin{tabular}{lcl}
\hline \multicolumn{1}{c}{ Voice of Customer } & $\begin{array}{c}\text { Tingkat } \\
\text { kepentingan }\end{array}$ & \multicolumn{1}{c}{ Technical Requirement } \\
\hline Kursi memenuhi posisi normal & 5 & Sesuai dengan bentuk punggung \\
Ketinggian dapat diukur & 5 & Kursi dapat dinaik turunkan \\
Terbuat dari bahan berkualitas & 5 & Memiliki bantalan \\
Suhu ruang terjaga & 5 & Memiliki AC \\
Memiliki fitur tambahan & 5 & Sandaran fleksibel \\
Ruang meletakkan barang & 4 & Jarak kursi tidak berdekatan \\
Kursi nyaman digunakan & 4 & Dapat menjangkau barang \\
Desain sesuai dengan ukuran & 4 & Desain dan ukuran yang sesuai \\
Ukuran sesuai dengan pengguna & 4 & Ukuran desain sesuai tubuh manusia \\
Mengurangi pergerakan & 4 & Dapat meletakkan barang disekitar \\
Kursi mudah digunakan & 4 & Mudah dipindahkan \\
Tidak melelahkan & 4 & Memiliki sandaran \\
Aman digunakan & 4 & Sudut kursi tidak tajam \\
Mempermudah perpindahan & 4 & Memiliki roda \\
Cahaya ruangan terjaga & 4 & Memiliki lampu \\
Dapat melakukan peregangan & 4 & Adanya jarak yang sesuai \\
Petunjuk penggunaan ada simbol & 4 & Penggunaan simbol \\
Kalimat SPJ pada petunjuk & 4 & Menggunakan kalimat yang singkat \\
\hline
\end{tabular}


Tabel $2 \mathrm{VoC}$, Tingkat KepentingandanTRMeja Tutorial

\begin{tabular}{lcl}
\hline \multicolumn{1}{c}{ Voice of Customer } & $\begin{array}{c}\text { Tingkat } \\
\text { kepentingan }\end{array}$ & \multicolumn{1}{c}{ Technical Requirement (TR) } \\
\hline Meja memenuhi posisi normal & 5 & Sesuai bentuk punggung \\
Ketinggian dapat diatur & 5 & Ketinggian dapat diatur \\
Meja aman digunakan & 5 & Siku meja dibuat tidak tajam \\
Intensitas cahaya ruangan terjaga & 5 & Ruangan memiliki lampu \\
Menggunakan simbol & 5 & Menggunakan symbol \\
Meja dapat menyimpan barang & 4 & Memiliki laci \\
Meja dapat menggantung tas & 4 & Adanya gantungan tas \\
Meja nyaman digunakan & 4 & Dapat menjangkau barang \\
Ukuran yang sesuai pengguna & 4 & Ukuran desain sesuai tubuh manusia \\
Mengurangi pergerakan & 4 & Dapat meletakkan barang diatasnya \\
Meja mudah digunakan & 4 & Meja mudah dipindahkan \\
Tersedia fitur tambahan & 4 & Memiliki pijakan kaki \\
Ruang gerak cukup & 4 & Memungkinkan pergerakan dimeja \\
Suhu ruangan terjaga & 4 & Ruangan memiliki AC \\
Dapat melakukan peregangan & 4 & Tersedia jarak \\
Menggunakan kalimat SPJ & 4 & Petunjuk penggunaan jelas \\
Meja terorganisir & 4 & Memiliki penyimpanan ATK \\
\hline
\end{tabular}

\subsection{Benchmarking}

Pada meja tutorial dilakukan perbandingan dengan meja laboratorium Ergonomi USU yang memiliki ketinggian $72 \mathrm{~cm}$ dengan antropometri dan meja tutorial ruangan 912 gedung FTI ITDel yang memiliki ketinggian $82 \mathrm{~cm}$. Perbandingan ini nantinya akan menjadi referensi untuk membuat meja tutorial yang berfokus pada pengggunaan normal dengan ukuran yang sesuai dengan pengguna dan meja mudah digunakan.Pada kursi tutorial dilakukan perbandingan dengan kursi ruangan 912 FTI ITDel dan Kursi Chitose cozy yang merupakan buatan pabrik. Ukuran kedua kursi tersebut disesuaikan dengan standar tersertifikasi SNI - Kursi lipat baja [25] untuk kursi ruangan 912 dan SNI-Kursi baja untuk kantor [26] untuk kursi chitose cozy. Kursi yang dibuat lebih unggul dari segi kesesuaian ukuran, bahan yang digunakan dan keamanannya. 


\subsection{House of Ergonomic}

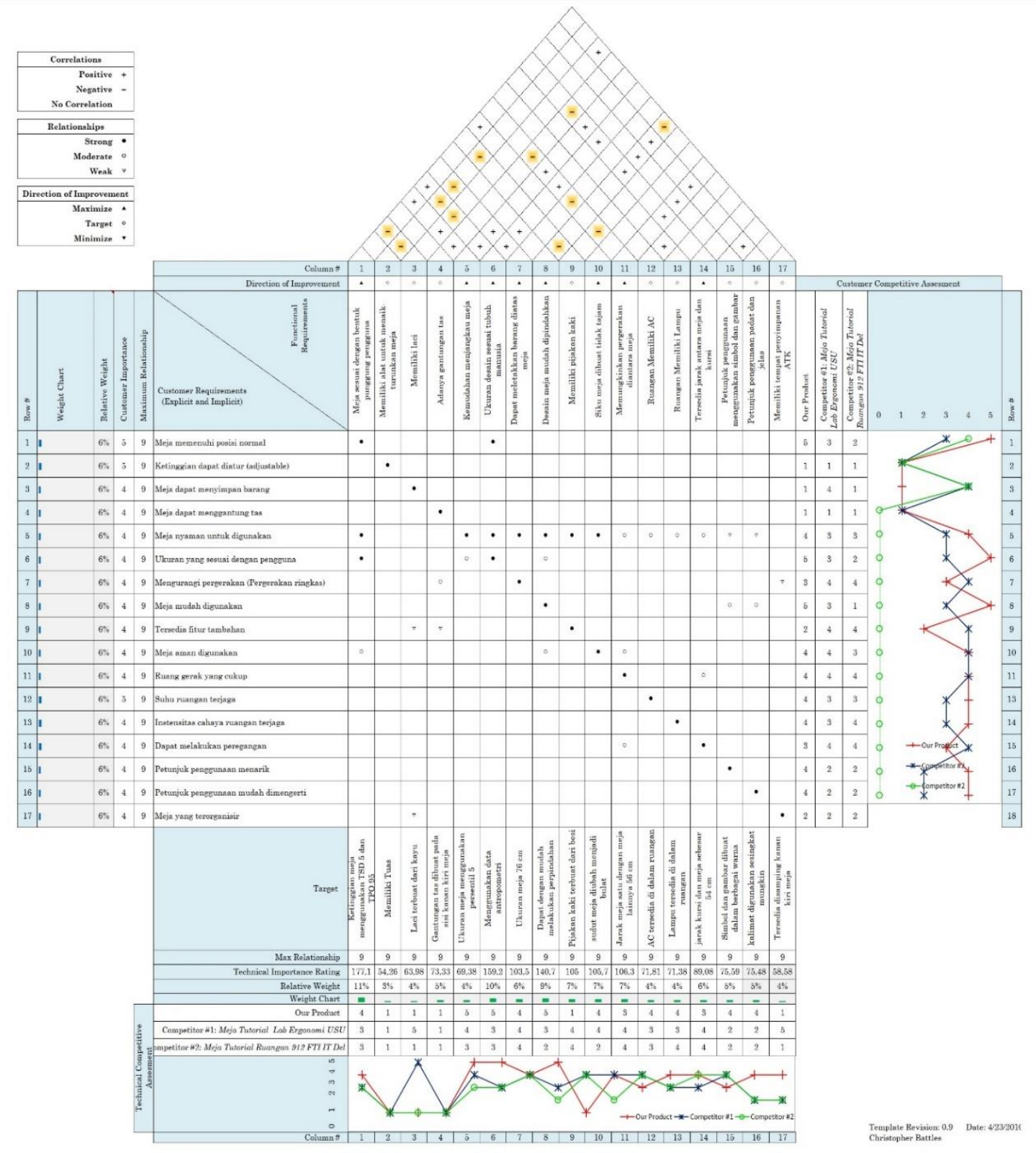

Gambar 2 House of Quality Meja Tutorial 


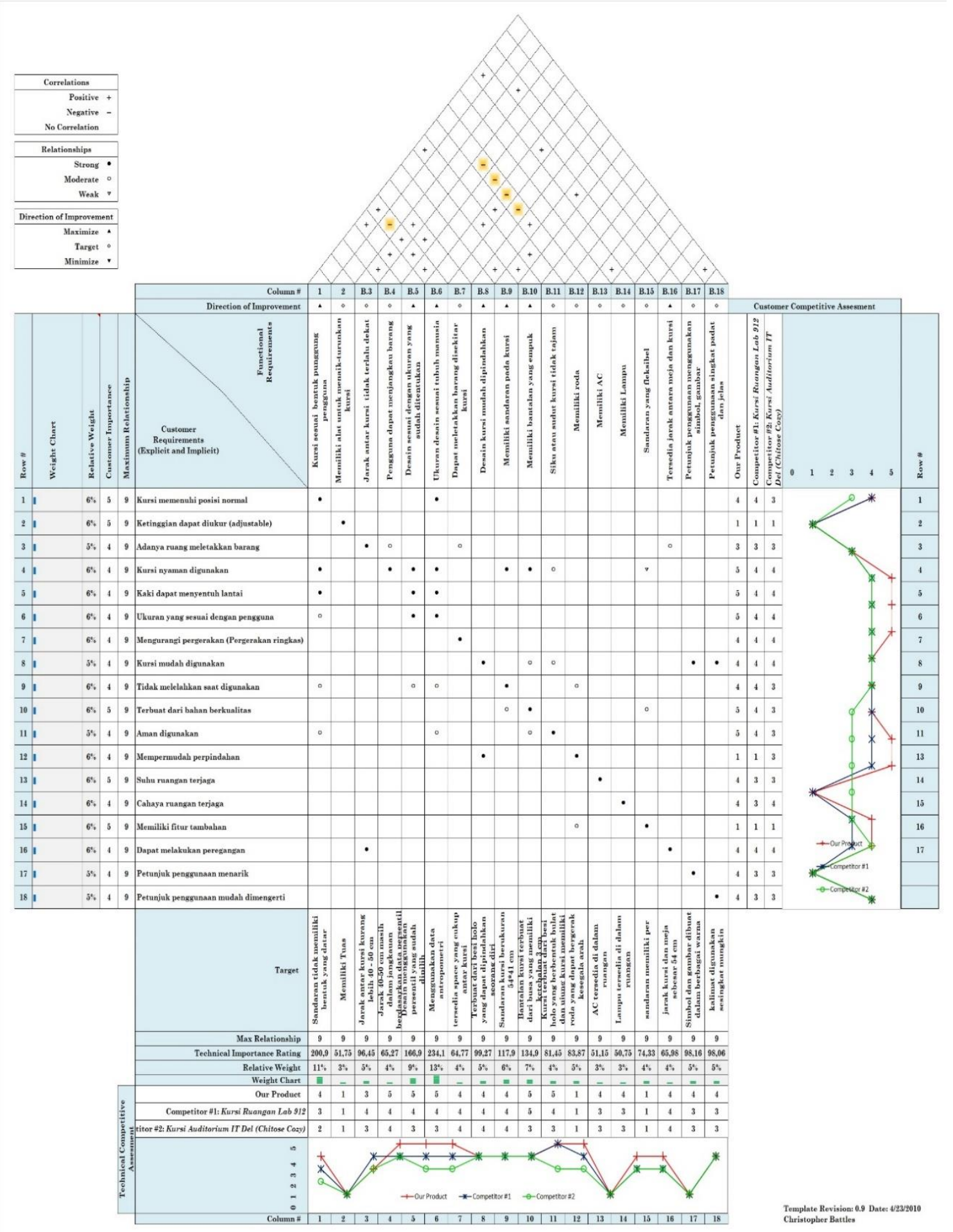

Gambar 3 House of Quality Kursi Tutorial

Pada house of ergonomic meja dan kursi tutorial yang telah dibuat (Gambar 3 dan 4) menunjukkan bahwa terdapat hubungan relasi antara teknikal respon dan atribut kebutuhan calon pengguna meja dan kursi. Data kebutuhan kursi tutorial terdapat 5 atribut dari 17 atribut yang memiliki nilai kepentingan sangat penting (nilai 5) yaitu pada kursi yang memenuhi posisi normal, ketinggian dapat diukur, terbuat dari bahan berkualitas, suhu ruang terjaga dan memiliki fitur tambahan. Sementara untuk meja tutorial memiliki 5 atribut dari 18 atribut yang memiliki nilai atribut yang sangat penting yang dimulai dari meja yang memenuhi posisi normal, ketinggian dapat diatur, 
meja yang aman digunakan, intensitas cahaya ruangan terjaga dan menggunakan simbol. Adapun prioritas upaya pengembangan dalam pembuatan meja dan kursi tutorial dapat dilihat pada kolom relative wight sejajar dengan kolom target.

\subsection{Uji Statistik Data Antropometri}

Berdasarkan hasil pengujian dengan menggunakan software SPSS ditemukan bahwa data antropometri yang diuji berdistribusi normal dengan data tidak ada yang lebih rendah dari nilai signifikansi $(0,05)$. Untuk pengujian keseragaman menunjukkan bahwa data berada diantara BKA dan BKB. Dengan menggunakan persentil 5, 50 dan 95 maka data antropometri tersebut dapat digunakan dalam mendesain meja dan kursi sebagai fasilitas dalam laboratorium (Tabel 3).

Tabel 3 Area Pengukuran, Persentil dan Dimensi dalam Desain

\begin{tabular}{cccccc}
\hline \multirow{2}{*}{ Area Pengukuran } & \multicolumn{3}{c}{ Persentil } & \multirow{2}{*}{ Kegunaan dalam Desain } \\
\cline { 2 - 4 } & $5^{\text {th }}$ & 50 th & 95 th & \\
\hline Tinggi Popliteal (Tp) & 36 & 40 & 44 & Ketinggian meja \\
Tinggi Siku Duduk (TSD) & 20 & 24 & 28 & Penjang meja \\
Rentangan & 152 & 165 & 178 & Ketinggian kursi \\
Tinggi Popliteal (TPO) & 36 & 40 & 44 & Lebar alas kursi \\
Lebar Pinggul (LP) & 28 & 33 & 38 & Panjang alas kursi \\
Panjang Popliteal (PP) & 40 & 45 & 50 & & Tinggi sandaran punggung \\
Tinggi Bahu Duduk (TBD) & 54 & 59 & 64 & \\
Lebar Bahu (LB) & 33 & 41 & 49 & Lebar sandaran punggung \\
\hline
\end{tabular}

Dalam membuat meja tutorial digunakan dimensi TSD dengan persentil 5, TPO persentil 95 dengan nilai toleransi $4 \mathrm{~cm}$ [27] sehingga ketinggian meja adalah $68 \mathrm{~cm}$. Untuk panjang meja menggunakan dimensi rentangan dengan persentil 5 sehingga berukuran $76 \mathrm{~cm}$.

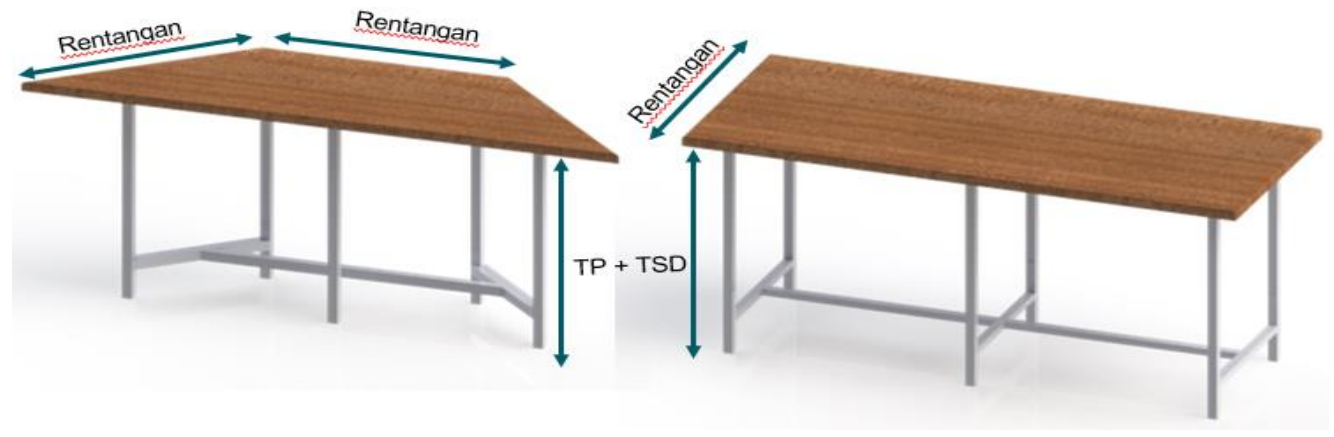

(a) (b)

Gambar 4 (a) Meja Trapesium, (b) Meja Persegi Panjang

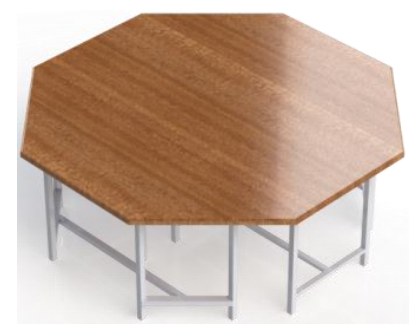

Gambar 5 Meja Digabungkan 
Untuk kursi tutorial menggunakan dimensi tinggi popliteal persentil 95 untuk ketinggian kursi, lebar pinggul persentil 95 untuk lebar alas kursi, panjang popliteal persentil 5 untuk panjang alas kursi, TBD persentil 50 untuk tinggi sandaran duduk dan LB persentil 50 untuk lebar sandaran duduk.

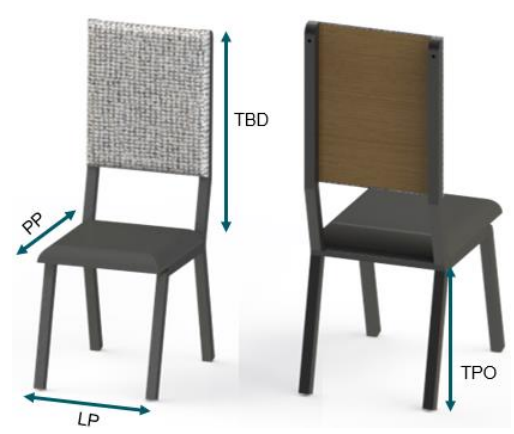

Gambar 6 Desain Kursi Tutorial

\section{Kesimpulan}

Dalam melakukan perancangan produk yang bersifat ergonomis maka perlu dilakukan kesesuaian antara 12 aspek ergonomi dengan produk yang dibuat. Berdasarkan hasil EFD yang menghasilkan HOQ ditemukan prioritas upaya pembuatan meja tutorial yang sesuai dengan kebutuhan konsumen melalui nilai persentase masing-masingrelative weight yaitu fokus kepada ketinggian meja dengan nilai persentil TSD 95 dan TPO 95 dengan adanya nilai toleransi yang digunakan yaitu $4 \mathrm{~cm}$, desain meja yang menggunakan antropometri, aman, hingga pemilihan material meja. Sedangkan pada kursi tutorial berfokus pada penggunaan data antropometri dalam pembuatan desain, bentuk sandaran dan bahan dudukan serta material kursi tutorial.

\section{DAFTAR PUSTAKA}

[1] H. Hafiar and J. N. Mahameruaji, "Tantangan Optimalisasi Peran Laboratorium Tv Di Perguruan Tinggi," Profetik J. Komun., vol. 10, no. 2, p. 80, 2017.

[2] K. Koespiadi, S. W. Mudjanarko, and F. Kurniawan, "Peningkatan Kualitas Kelulusan Pendidikan Tinggi Untuk Memenuhi Kebutuhan Pasar Jasa Konstruksi Di Indonesia," Narotama, J. Tek. Sipil, vol. 1, no. 2, pp. 17-27, 2014.

[3] N. L. P. Kertiasih, "Peranan Laboratorium Pendidikan Untuk Menunjang Proses Perkuliahan Jurusan Keperawatan Gigi Poltekkes Denpasar," Jurnal Kesehatan gigi, vol. 4, no. 2. Bali, pp. 59-66, 2016.

[4] M. R. Asmawi, "Strategi Meningkatkan Lulusan Bermutu Di Perguruan Tinggi," Makara Hum. Behav. Stud. Asia, vol. 9, no. 2, p. 66, 2005.

[5] N. Nilamsari, Soebijanto;, Lientje, and Setokoesoemo B.R, "Bangku ergonomis untuk memperbaiki posisi duduk siswa sman di kabupaten gresik (," J. Ners, vol. 10, no. 1, pp. 87-103, 2015.

[6] S. T. Putri, S. Solichin, and E. Fanani, "Pengaruh Redesain Kursi Gazebo Fik Yang Ergonomis Terhadap Musculoskeletal Disorder," Prev. Indones. J. Public Heal., vol. 3, no. 1, p. 35, 2018.

[7] P. W. Mustika and I. M. Sutajaya, "Ergonomi Dalam Pembelajaran Menunjang Profesionalisme Guru Di Era Global," JPI (Jurnal Pendidik. Indones., vol. 5, no. 1, p. 82, 2016.

[8] G. P. Liansari, A. Febrianti, and P. A. Tama, "Usulan Rancangan House Of Ergonomic (HOE) Produk Interior Toilet Gerbong Kereta Penumpang Kelas Ekonomi Menggunakan 
Metode Ergonomic Function Deployment (EFD)," J. PASTI, vol. XII, no. 1, pp. 1-15, 2017.

[9] H. Irdiastadi and Yassierli, Ergonomi Suatu Pengantar. Bandung: PT Remaja Rosdakarya, 2014.

[10] B. S. Putri and L. Kartika, "Pengaruh Kualitas Pelayanan Bpjs Kesehatan Terhadap Kepuasan Pengguna Perspektif Dokter Rumah Sakit Hermina Bogor,” J. Ris. Manaj. dan Bisnis Fak. Ekon. UNIAT, vol. 2, no. 1, pp. 1-12, 2017.

[11] A. Santoso, B. Anna, and A. Purbasari, "Perancangan Ulang Kursi Antropometri Untuk Memenuhi Standar Pengukuran," Profesiensi, vol. 2, no. 2, pp. 81-91, 2014.

[12] A. M. Hashim and S. Z. M. Dawal, "Kano Model and QFD integration approach for Ergonomic Design Improvement," Procedia - Soc. Behav. Sci., vol. 57, pp. 22-32, 2012.

[13] O. Panjaitan and Y. Manik, "Aplikasi Quality Function Deployment (QFD) dalam Mendesain Produk Turunan Andaliman," Talent. Conf. Ser. Energy Eng., vol. 2, no. 3, pp. 40-58, 2019.

[14] M. Hanafi, R. D. Astuti, and I. Iftadi, "Perancangan Ulang Fasilitas Kerja Alat Pembuat Gerabah dengan Mempertimbangkan Aspek Ergonomi," Performa 2011, vol. 10, no. 1, pp. 11-18, 2011.

[15] D. MacLeod, The Rules of Work A Practical Engineering Guide to Ergonomic, Second Edi. Boca Raton, Florida: CRC Press, 2012.

[16] B. A. H. Siboro, Suroso, Suhendrianto, and Esmijati, "Penerapan 12 Prinsip Ergonomi pada Ruang Server (Studi Kasus Ruang Server Universitas Gadjah Mada)," Profisiensi, vol. 1, no. 1, 2013.

[17] K. K. Kroemer, K; Kroemer, H; Elbert, Ergonomic Ease-Efficiency Work.pdf. New Jersey: Prentice Hall, 2001.

[18] M. A. Wijaya, B. A. H. Siboro, and A. Purbasari, "Analisa Perbandingan Antropometri Bentuk Tubuh Mahasiswa Pekerja Galangan Kapal dan Mahasiswa Pekerja Elektronika," Profisiensi, vol. 4, no. 2, pp. 108-117, 2016.

[19] Fitra, Desyanti, and M. Suhaidi, "Penerapan Data Antropometri Siswa Dalam Perancangan Tempat Berwhudu di SDIT ATH Thaariq - 2 Dumai," J-ABDIPAMAS (Jurnal Pengabdi. Kpd. Masyarakat), vol. 4, no. 1, pp. 1-10, 2020.

[20] S. Rahayuningsih and S. A. Sari, "Perancangan Kursi Dan Meja Lipat Untuk Mahasiswa ( Studi Kasus: Mahasiswa Universitas Kadiri )," in Prosiding Semnastek (Seminar Nasional Sains dan Teknologi), 2018, vol. 1, pp. 4-8.

[21] W. Widhiarso, "Tanya Jawab tentang Uji Normalitas," Fak. Psikol. UGM, pp. 1-5, 2012.

[22] M. A. Oktaviani and H. B. Notobroto, "Perbandingan Tingkat Konsistensi Normalitas Distribusi Metode Kolmogorov-Smirnov, Lilliefors, Shapiro-Wilk, dan SkewnessKurtosis," J. Biometrika dan Kependud., vol. 3, no. 2, pp. 127-135, 2014.

[23] D. I. Rinawati, D. Puspitasari, and F. Muljadi, "Penentuan Waktu Standar Dan Jumlah Tenaga Kerja Optimal Pada Produksi Batik Cap (Studi Kasus: Ikm Batik Saud Effendy, Laweyan),"J@Ti Undip J. Tek. Ind., vol. 7, no. 3, pp. 143-150, 2013.

[24] N. Nurhasanah, F. Zakky Haidar, S. Hidayat, N. Hasanati, A. Putri Listianingsih, and D. Utami Agustini, "Penjadwalan Produksi Industri Garmen Dengan Simulasi Flexsim," J. Ilm. Tek. Ind., vol. 2, no. 3, pp. 141-148, 2014.

[25] P. C. I. TBK, "Folding Chair," [Online]. Availabe: https://www.chitoseindonesia.com/kategori/folding-chair/ [Accessed: Oct.7, 2019].

[26] Badan Standarisasi Nasional, Penetapan Standar Nasional Indonesia 8780:2019 Furniture - Kursi Kerja Kantor sebagai Revisi dari Standar Nasional Indonesia 12-01791987 Kursi Baja untuk Kantor dan Standar Nasional Indonesia 12-2992-1992 Kursi Kerja Kayu untuk Kantor [Online].Available:https://aksessispk.bsn.go.id/Upload/Dokumen/SK_SNI/SK_SNI_384_KEP_BSN_8_2019.pdf [Accessed: Oct.7, 2019]

[27] Hermanto, S. Sinambela, and M. Irvan, "Usulan Rancangan Ukuran Pada Meja dan Kursi Lipat Belajar Yang Ergonomis Untuk Rumah Petak di Jakarta," J. Tek. Ind., vol. 1, no. 2, pp. 9-15, 2017. 